\title{
Determinants of Route Choice and Value of Traveler Information A Field Experiment
}

\author{
Lei Zhang and David Levinson
}

\begin{abstract}
Drivers receive value from traveler information in several ways, including the ability to save time, but perhaps more important is the value of certainty as it affects other personal, social, safety, or psychological factors. This information can be economically valued. The benefit of reduction in driver uncertainty when information is provided at the beginning of the trip is the main variable measured in this research. User preferences for routes were assessed as a function of the presence and accuracy of information while controlling for other trip and route attributes. Data were collected in a field experiment in which 113 drivers, given real-time travel time information with varying degrees of accuracy, drove four alternative routes between a preselected origindestination pair in the Twin Cities, Minnesota, metropolitan area. Ordinary regression, multinomial, and rank-ordered logit models produced estimates of the value of information with some variation. Results showed that travelers were willing to pay up to $\$ 1$ per trip for pretrip travel-time information. The value of information is higher for commute and event trips and when congestion on the usual route is heavier. The accuracy of the traveler information was also a crucial factor. Travelers will not pay for information unless they perceive it to be accurate. Most travelers (70\%) prefer that such information be provided free by the public sector, whereas some $(19 \%)$ believe that it is better for the private sector to provide such service at a charge.
\end{abstract}

Traffic delays are inevitable given that traffic levels are increasing at a rate faster than new roadways are being built. Advanced travelers information systems (ATIS) and advanced traffic management systems (ATMS) have been proposed and implemented in several metropolitan areas to help mitigate congestion. The two types of systems are often integrated because the successful operation of both requires a sensor network that collects real-time traffic data and an online data analysis package that identifies the current or predicts the future states of the system. However, they differ in how the system state information is used. ATIS communicates the information, such as travel time between an origin-destination (O-D) pair on alternative routes, to individual users through various means in an attempt to help them

L. Zhang, School of Civil and Construction Engineering, Oregon State University, 220 Owen Hall, Corvallis, OR 97331. Current affiliation: Department of Civil and Environmental Engineering, University of Maryland, College Park, MD 20742. D. Levinson, Department of Civil Engineering, University of Minnesota, 500 Pillsbury Drive Southeast, Minneapolis, MN 55455. Corresponding author: L. Zhang, lei@umd.edu.

Transportation Research Record: Journal of the Transportation Research Board, No. 2086, Transportation Research Board of the National Academies, Washington, D.C., 2008, pp. 81-92.

DOI: $10.3141 / 2086-10$ make better travel-related decisions. ATMS in general takes advantage of the information by operating traffic control devices such as traffic lights, ramp meters, and incident management. ATMS sometimes also refers to advanced transportation management systems or automated transportation management systems. In those cases, it usually encompasses both ATIS and ATMS in the narrower sense.

The objective of this research is to investigate the factors influencing route choice (including ATIS) to assess the value of traveler information for motorists, and to understand public acceptance of ATIS. The large body of literature that has examined similar issues is reviewed in the following section. Although these studies tried to estimate the benefits of traveler information, they all did so at a theoretical level or in a simulation context and generally attempted to measure time saved. This research extends the previous research in two important and practical directions. First, the data for this study were collected in a comprehensive field experiment. In the experiment, a large number of travelers, with or without pretrip information, drove both freeway and arterial routes in a large real-world network, assessed the information, evaluated the importance of information accuracy, and revealed their route preferences for various trip purposes. Second, the focus of this study was to derive the value of traveler information under different circumstances or users' willingness to pay for information services. By the very nature of the design, the value of information was not considered directly in terms of observed or computed time savings but rather in perceived reduction of time cost and uncertainty.

Users should be willing to pay for traveler information because such services can reduce travel costs, uncertainty, and anxiety. The benefits of ATIS to users therefore are in terms of not only time and monetary savings, but also emotional and psychological well-being. There are several reasons why it is important to understand users' willingness to pay for traveler information. First of all, the true benefits of ATIS cannot be appropriately evaluated without a thorough understanding about willingness to pay and consumers' surplus. Second, market share is an important factor determining the effects of ATIS on the system performance, which is the result of the direct interplay of willingness to pay and the cost of acquiring traveler information. Finally, knowing how much users want to pay for traveler information is necessary for the design of sustainable for-profit private or public-private partnership ATIS services.

This research will also help in understanding the route selection process with and without traveler information for different trip purposes. Regression analysis and discrete choice models were the primary methodological tools. The information gained from this study will enable transportation engineers to design future information systems in ways that reduce driver frustration. Reduced driver frustration also is likely to lead to fewer aggressive driving incidents. 


\section{LITERATURE REVIEW}

Travelers rely on their spatial knowledge about the physical and built environment to make travel-related decisions, such as job and residential location, vehicle ownership, activity schedule, activity location, travel model, and routes. The decision-making process is also typically subject to a number of determinants and constraints imposed by the physical, built, economic, and societal environment, as well as the imperfection of travelers' perception and cognition capabilities $(1,2)$. Information plays a key role in travelers' perception, cognition, and decision-making processes. Travelers learn about the environment through various information sources, including personal experience, interpersonal communication, maps, and mass media. ATIS has the potential to improve travelers' decisionmaking process by providing relevant real-time information about the state of the transportation system.

At the individual level, users can benefit from ATIS in terms of travel-time savings and travel certainty (3). Because a number of previous studies have explored theoretical and estimation issues with regard to the value of travel-time (4-9) and the value of travel-time variation $(10,11)$, the two components of the value of traveler information may be estimated separately. Many researchers have attempted to estimate the travel-time savings with ATIS technologies (3, 12-19). Although their findings suggest ATIS could reduce travel time for equipped vehicles and overall, under nonrecurrent and recurrent congestion conditions, and with various level of market penetration, several studies concluded that ATIS by itself should not be considered to be a solution to peak-period congestion problem or as an effective alternative to traditional capacity expansion $(3,20)$. The value of reduced travel uncertainty under ATIS, however, has not been rigorously examined and incorporated into ATIS studies. Alternatively, the two components of the value of traveler information may be estimated together by a willingness-to-pay measure. This approach has been explored in several studies on the basis of stated preference surveys in which travelers were asked directly how much they were willing to pay for specific ATIS services $(21,22)$. Choice models also have been previously developed to estimate users' willingness to pay for traveler information (23).

At the agency level, the decision to adopt ATIS usually involves estimation of user benefits, social benefits, and implementation costs, as well as several other important policy issues. When the majority of the drivers are risk-averse, in that they may travel more with improved travel-time reliability but slightly increased average journey time, the implementation of ATIS could, in some cases, hurt the uninformed drivers (3). There might be a horizontal equity issue in this regard. There have also been discussions on the nature of ATIS. Hall argued that ATIS should be viewed first as a service to the public and second as a means for steering traffic toward user optima that uses feasible alternate routes (24). Al-Deek et al. found that traffic diversion with ATIS may reduce overall safety because more drivers use less safe arterial streets (25). Khattak et al. provided a discussion of various design and evaluation issues related to ATIS (26).

The provision of traveler information by ATIS can induce a number of possible short-run responses from the users. Travelers, knowing the level of congestion on alternative routes, may decide not to travel at all, change destinations, change departure times, change modes, and change routes. So far, no evidence suggests that ATIS could significantly affect long-term behavior such as job and residential locations. Most previous studies examined the impacts of ATIS on route choice and traffic equilibrium $(3,13,23,27-48)$. One study explored the effects of ATIS on destination and route choices for shopping trips (49).
This is not surprising, because it is conceivable that the most significant impacts of ATIS would be on route choices. These studies differ in assumptions about users' responses to information (routeswitching behavior, fixed and variable O-D demand), traffic assignment criteria for informed and uninformed drivers (e.g., user optimal, stochastic user equilibrium, social optimal), quality of the information (perfect and imperfect), types of congestion (recurring and nonrecurring), market penetration of equipped vehicles (endogenous and exogenous), and properties of the traffic models (e.g., static, dynamic, and queuing models). Most studies make unverified assumptions about driver behavior; few studies discuss the importance of laboratory and field experiments (50). In general, previous findings suggest that the success of ATIS depends on users' responses, accuracy of information, customization of information, percentage of informed drivers, availability of alternative routes, level and types of congestion, and the magnitude of induced demand.

Various types of ATIS services have been proposed and explored in previous studies. Traveler information can be provided before a trip (pretrip or origin-based) is made or en route (51). Different types of information can be provided ranging from accident alert, traveltime estimates on alternative routes, and route-guidance information, to more comprehensive organized information about a tour or an activity plan. Currently, most passenger ATIS services are provided through one-way communication such as radio, television, Internet, and variable message signs (VMS). In-vehicle route guidance systems allow users to identify the desirable destination and route. More advanced location-based services allow users to specify a set of activities and time budget (52). Commercial ATIS services are provided through two-way communication enabling information exchange between vehicle operators and dispatchers (53). ATIS can be provided by for-profit private companies (42), by the pubic sector, through a public-private partnership (54), or through a club-type organization (55). A number of state departments of transportation in the United States provide real-time traffic information through radio, television, Internet, and 511 services. Other noteworthy ATIS projects include the CALTRANS Smart Traveler in Los Angeles, California, (56), TravTek in Orlando, Florida, (57), ADVANCE in Chicago, Illinois, (58), and FASTTRAC in Michigan (59). In Europe, STORM has been implemented in Stuttgart, Germany (17).

\section{EXPERIMENT DESIGN AND DATA}

The experiment for this project was designed using both stated preference survey techniques and field experiment, called field experience stated preference.

Five routes between the University of Minnesota East Bank Campus and downtown Saint Paul in the Twin Cities metropolitan area were selected for a field route choice experiment conducted in spring 2004 (Figure 1). The routes are roughly parallel and provide reasonable ways to go between the origin and the destination. One of the routes is a freeway (I-94), and four other routes are signalized arterial streets. One of the selected arterial streets (Summit Avenue) is notably more scenic than other routes. One of the selected arterial streets (Grand Avenue) has notably more commercial development (grocery and specialty shops) than other routes. The five routes selected constitute an important corridor in the Twin Cities connecting downtown Minneapolis and downtown Saint Paul. The level of congestion during peak periods on this corridor is moderate or heavy at times.

Subjects were selected randomly from the University of Minnesota staff list (excluding faculty and students affiliated with the Department of Civil Engineering or the Human Factors Laboratory). Each subject 


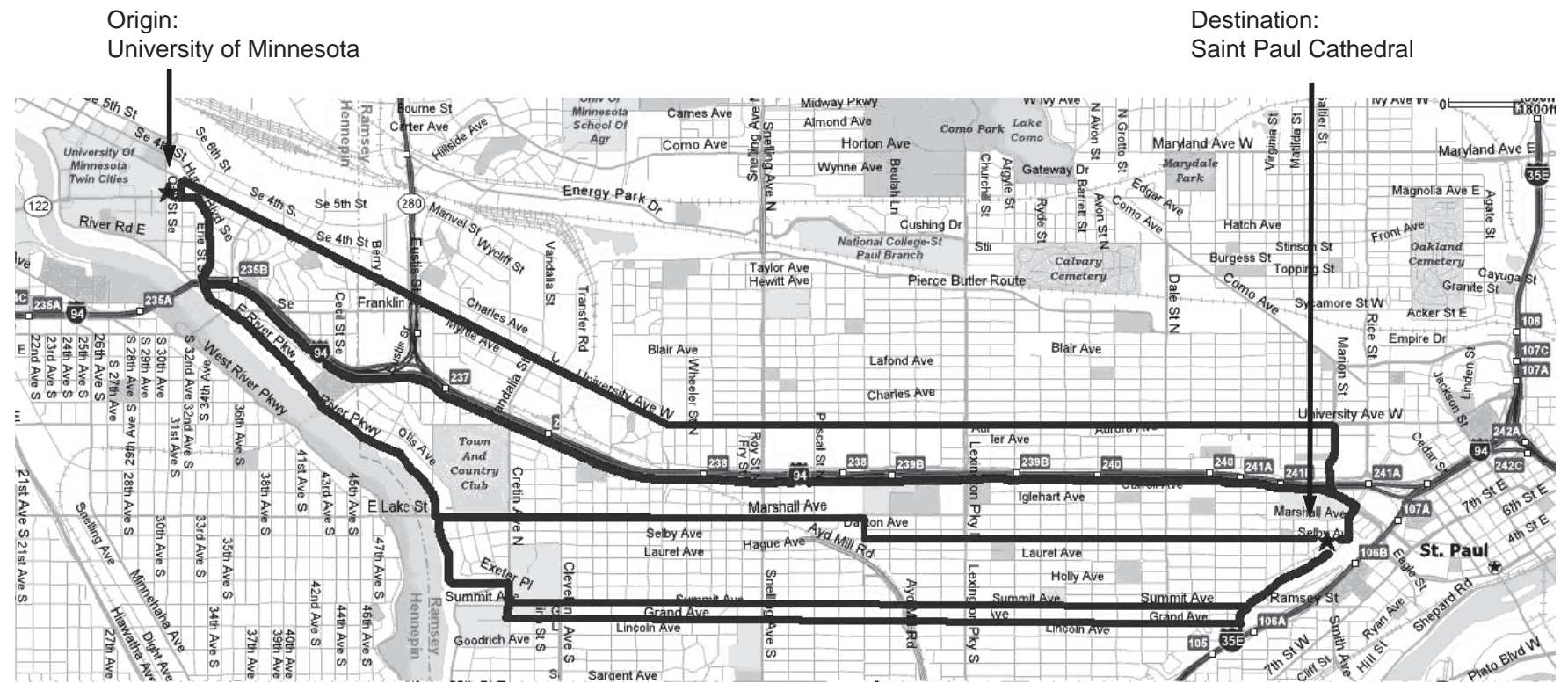

FIGURE 1 Selected routes for field experiments.

was given a pretest to gather various socioeconomic, demographic, vehicle, and preference data. Subjects also filled out a standard 1-day travel diary so that their daily activity travel patterns could be known. A summary of the sociodemographic features of the final sample is provided in Table 1. There is sufficient variation in age, gender, education, income, household structure, and travel patterns among the selected subjects. The sample is representative of the general driving population, except that the level of education of the subjects is a bit high. A larger sample size should improve the accuracy of the findings, even though this sample with 113 subjects is sufficiently large to develop statistically significant models. Their vehicles were then temporarily equipped with a recording global positioning system (GPS) unit, which collected vehicle location data at 1-s intervals and allowed the researchers to track the route actually taken by each subject. To encourage their participation, each subject received a small cash reward $(\$ 50)$. The recruitment of subjects for field experiments or survey studies could be an issue. Interested readers are referred to Bhat et al. (50), who discussed driver recruitability for ATIS-related experiments based on telephone surveys.

During the field experiment, each subject was advised to take one of the five selected routes from the origin to the destination. After completing the outbound journey, each subject returned to the origin point using a second route. Then each subject took a second round trip using two new routes between the origin and destination points. At the end of the experiment, each subject took four of the five selected routes. Approximately half of the subjects were provided with information about the expected travel time before their trips. The traveltime information for each route was obtained from probe vehicles before the experiment and did not reflect real-time traffic conditions during the field experiment. Therefore, this information may or may not be accurate because of the variation of the level of congestion at times when the subjects actually made their trips.

The GPS data were logged into a data capture device, which allows the researchers $(a)$ to confirm that the subjects traveled the correct route; $(b)$ to obtain actual route or trip attributes such as total travel time, distance, number of stops, stopped waiting time, and speed; and $(c)$ to assess the true accuracy of the travel-time information provided to the subjects. At the destination, the subjects were asked a number of questions rating trip quality in an absolute sense and in comparison with other trips they made as part of the experiment. Each subject rated (on a 7-point scale) and ranked the four routes traveled for several different trip purposes including commute, event, shopping, recreational, social or visit, and Sunday drive. They also reported their perceived travel time, distance, number of stops, and speed for the routes they traveled after each route trip. These data were collected to help develop models of drivers' route perception process. Finally, they rated the efficiency, easiness, pleasure, and familiarity of the traveled routes on a 7-point scale. This information can be used to develop models of drivers' route cognition process. When combined with observed and perceived route attributes and subjects' final decision, it can help develop behavioral theories and behavioral models of route choice.

Subjects who were given information were also asked about the usefulness and their perceived accuracy of the pretrip travel-time information. They also revealed how often they would use such information if it were provided as a regular service, how much they would be willing to pay for the service, and who they think should provide the service. Finally they rated the importance of travel-time information for various trip purposes mentioned previously.

\section{METHODOLOGY}

Two sets of statistical models were derived. The first set of models described how drivers' route preferences vary with the presence and accuracy of information, while controlling for observed or perceived route attributes such as travel time, number of stops, stopped delay, specific route, car (e.g., make, model, age of car), and demographics (e.g., age, gender, household size). The second set of models correlated drivers' propensity to the usage of traveler information with the quality of information and drivers' attitudes, socioeconomic, demographic, travel behavioral, and other factors. 
TABLE 1 Descriptive Statistics of Research Subjects

\begin{tabular}{|c|c|}
\hline Variable & No. \\
\hline \multicolumn{2}{|l|}{ Gender } \\
\hline Women & 58 \\
\hline Men & 55 \\
\hline \multicolumn{2}{|l|}{ Household income, \$ } \\
\hline$<50,000$ & 36 \\
\hline $50,000-100,000$ & 58 \\
\hline$>100,000$ & 19 \\
\hline \multicolumn{2}{|l|}{ Age, years } \\
\hline$<35$ & 37 \\
\hline $35-55$ & 58 \\
\hline$>55$ & 18 \\
\hline \multicolumn{2}{|l|}{ Education } \\
\hline$<2$ years of college & 27 \\
\hline $2-4$ years of college & 41 \\
\hline Postgraduate & 45 \\
\hline \multicolumn{2}{|l|}{ Household size, people } \\
\hline 1 & 23 \\
\hline 2 & 48 \\
\hline 3 & 20 \\
\hline$\geq 4$ & 22 \\
\hline \multicolumn{2}{|c|}{ Household number of autos } \\
\hline 1 & 28 \\
\hline 2 & 65 \\
\hline 3 & 12 \\
\hline$\geq 4$ & 8 \\
\hline \multicolumn{2}{|l|}{ Commute time, mi } \\
\hline 10 & 3 \\
\hline 20 & 29 \\
\hline 30 & 42 \\
\hline 40 & 23 \\
\hline$>40$ & 16 \\
\hline \multicolumn{2}{|l|}{ Commute distance, mi } \\
\hline 5 & 14 \\
\hline 10 & 39 \\
\hline 15 & 29 \\
\hline 20 & 14 \\
\hline$>20$ & 17 \\
\hline \multicolumn{2}{|l|}{ Trips per day } \\
\hline 2 & 13 \\
\hline 5 & 37 \\
\hline 10 & 55 \\
\hline$>10$ & 8 \\
\hline \multicolumn{2}{|l|}{ Years in city } \\
\hline 5 & 16 \\
\hline 10 & 16 \\
\hline 20 & 23 \\
\hline 30 & 16 \\
\hline$>30$ & 42 \\
\hline
\end{tabular}

\section{Route Choice and Traveler Information}

Choice behavior in the transportation literature is often depicted as a two-stage process. First, a choice set generation process determines the feasible alternatives known and considered by the decision maker for a choice situation. Then a choice criterion is assumed that eliminates inferior alternatives until the best alternative is identified. Dominance, satisfaction, lexicographic rules, elimination by aspects, heuristic production rules (if . . . then . . .), and utility maximization are the most common decision protocols (60-63). The analysis of route choice behavior in this report assumed that travelers were util- ity maximizers. Future research may develop route choice models based on the same data set and other decision criteria and make comparisons.

Random utility theory (64) states that utility has two parts: an observable deterministic component and an unobservable random component. The probability of choosing an alternative is equal to the probability that the utility of that alternative is greater than or equal to the utilities of all other considered alternatives. The deterministic or systematic utility of a route being considered by a traveler is as follows

$U=f(T, V, I, A, P, R, N, D, K, E, B, Q, C, S, H, F, X)$

where

$T=$ travel time,

$V=$ variation in travel time from expectations,

$I=$ precommute information about travel time (with or without),

$A=$ accuracy of information (rated on a 7-point scale by subjects and measure by GPS),

$P=$ trip purpose,

$R=$ number of stops,

$N=$ number of turns,

$D=$ total delay,

$K=$ density of surrounding traffic,

$E=$ environmental factors (e.g., weather),

$B=$ road type (e.g., residential, signalized arterial, freeway),

$Q=$ aesthetic quality of the roadside environment (high or low),

$C=$ level of commercial development along the route (high or low),

$S=$ safety of the road (e.g., accidents),

$H=$ hour of day (e.g., personal safety concerns),

$F=$ familiarity with route (rated on a 7-point scale), and

$\boldsymbol{X}=$ socioeconomic and demographic factors describing individual driver.

The method most widely used to operationalize random utility theory is discrete choice modeling. McFadden applied the logit model to prediction of individual mode choice (65). Discrete choice models have been continuously improved to address many econometric issues. Binary, multinomial, and rank-ordered logit models were specified in this study to deal with different response variables.

Each subject ranked the four routes traveled for different trip purposes. The rank-ordered logit model takes the rank of routes as the dependent variable. It is sometimes referred to as the Placket-Luce or exploded logit model. Rank-ordered choice models are of particular interest in survey research because of their cost-effectiveness. They fully use the ranks of all alternatives, rather than just the most preferred one as in multinomial logit models, so that more information is collected per observation $(66)$. The probability $(P)$ that a subject ranks all four alternatives in a choice set in a specific order $w$ is

$P[W=w \mid \beta]=\prod_{i=1}^{4} \frac{\exp \left(U_{w_{i}}\right)}{\sum_{w_{i}}^{w_{4}} \exp \left(U_{w_{i}}\right)}$

where $w_{i}$ is the $i$ th alternative in the ranking. If choice $i$ is the most preferred and has been ranked first, the choice that is ranked second would then be the most preferred among the remaining alternatives. The probability density and log-likelihood functions of a rank ordered logit model are similar to those of a traditional multinomial logit model. One concern with ranked responses is that the subjects may care only about the most preferred alternative and thus the rank infor- 
mation for the remaining alternatives may not be reliable. For confirmation purposes, therefore, multinomial logit models in which the information about the relative desirableness of the three unselected alternatives is not used were also estimated.

Discrete choice models consider utility as an ordinal measure. The notion of cardinal utility is sometimes useful, because the subjects also rated the routes on a 7-point scale in addition to ranking the routes. The rated score can be considered as a cardinal utility measure. In that case, an ordinary regression model can be specified based on Equation 1 directly for each route and for each trip purpose. This not only provides a means to confirm results obtained from the discrete choice models but also allows the researcher to examine the variation of the value of information by route attributes. However, the scores rated by the subjects tend to display different means and variations. To avoid issues related to nonzero mean and heteroscedasticity, the scores are standardized for each individual subject, and the standardized score is used as the dependent variable in the regression models.

To operationalize the proposed theory of route choice, the perception and cognition processes for learning routes in a network, and route attributes must be explicitly modeled. Figure 2 shows how a traveler makes a route choice decision given actual attributes of one or more routes. Various protocols of choice act mentioned earlier in this section relate the objective reality - that is, observed route attributes - to the final choice in different ways. However, in general they ignore the perception and cognition processes.

The statistical models described previously can identify the importance of various factors on route preference. The elasticity between information and travel cost derived from the models should provide a way of measuring the value of traveler information differentiated by trip purposes and by various route attributes.

\section{Information Usage and Public Acceptance of Traveler Information Systems}

The success of ATIS depends on the public acceptance of and demand for the technology. ATIS service providers, private or public, want to know the characteristics of drivers who are likely to frequently use traveler information. To address those issues, a number of questions regarding the usage of, attitude toward, and willingness to pay for traveler information services are included in the after-experiment survey. A summary of the subjects' answers to these questions is provided in the results section. A binary choice model is also specified to examine the factors affecting the usage of traveler information ( $1=$ will use traveler information; $0=$ will not use traveler information). The utility of driving with or without traveler information is as follows:

$U=f(A, G, F, L, Z, \boldsymbol{M}, \boldsymbol{X})$

where

$A=$ accuracy of information,

$G=$ attitude toward traveler information (perceived usefulness),

$F=$ familiarity with alternative routes,

$L=$ level of congestion,

$Z=$ perceived information acquisition and processing cost, and

$\boldsymbol{M}=$ travel patterns (e.g., commute time, distance, trip frequency).

Perceived information acquisition and processing cost should have a negative effect on the usage of traveler information. In the experiment, information is provided to the subjects for free. Therefore, $Z$ in this case is simply the perceived information processing cost, which is unobservable and becomes a part of the random component in the model. But its average effects on information usage should contribute to the constant term in the binary choice model.

An ordinary regression model can also be specified and estimated with the frequency of using information $(Y)$ as the dependent variable (rated on a 6-point scale, where $1=$ less than once per week and $6=$ several times per day).

$Y=f(A, G, F, L, Z, M, X)$

Results of regression Model 4 should agree with the results of the binary logit model on the basis of utility Function 3 if subjects provided consistent answers in the survey.

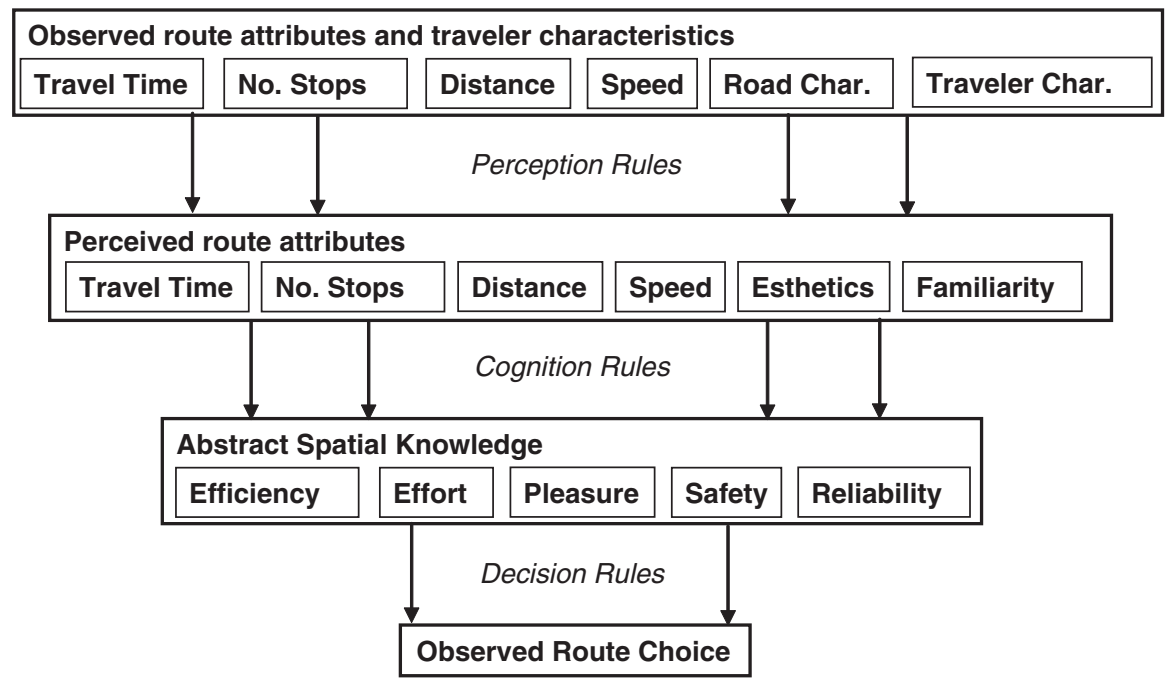

FIGURE 2 Route perception and cognition. 


\section{RESULTS}

\section{Importance of Various Route Attributes for Trips with Different Purposes}

All coefficients in the rank-ordered, multinomial, and ordinary regression models of route choice have expected signs. For all trip purposes, drivers are more likely to choose a route that has (observed and perceived) lower travel time, higher speed, fewer number of stops, and better esthetics (Tables 2 and 3). Drivers also prefer routes that are efficient, easy to drive, pleasant, and familiar (Tables 2, 3, and 4). The only exception is that the variable actual distance has positive signs in Tables 2 and 3. The fact that all five routes selected for the field experiment have very similar total distances may cause the unexpected signs. However, variable perceived distance in general has expected negative signs in Tables 2 and 3. Clearly, the perceived distance is different from the actual distance traveled. Subjects appear to have perception biases and have systematically misperceived the distances of some routes. The relationship between actual and perceived route attributes is the topic of an ongoing study.

It is also evident from the results that the importance of route attributes (actual and perceived) varies with trip purposes. Efficiency- related attributes such as travel time, distance, and number of stops are considered more important for commute, event, and visit trips and less important or even insignificant for shopping and recreational trips. Enhanced roadside esthetics make a route more attractive for all types of trips and have the most significant effect on recreational trips. Level of commercial development is positively related to the attractiveness of route for shopping trips, whereas its impacts on other types of trips are not significant. There is also evidence of habitual route choice behavior, especially for trips with time pressure. When making commute, event, and visit trips, drivers tend to choose a route they are more familiar with than unfamiliar routes. One explanation is that under time pressure, drivers prefer a more reliable route, and they perceive routes they are familiar with and have used before to be more reliable. Another explanation is the anchoring effects of firstnoticed routes as discussed by Golledge (67). Once a driver becomes familiar with a route, he or she has little incentive to switch to a new route with comparable or even slightly better performance because of perceived information acquisition and processing cost, perception threshold, and risk averseness. Several previous studies suggest that travel time is only one of many factors affecting route choice $(65,68-71)$ and that the relative importance of those factors varies by trip purposes $(72,73)$, type of driver $(74)$, trip distance, and duration

TABLE 2 Results: Rank-Order Logit Models

\begin{tabular}{lccccc}
\hline Purpose & Commute Trip & Event & Shopping & Recreation & Visit \\
\hline Route Rank $=f$ (observed route attributes, dummy & variable, information) & & \\
\hline Esthetics & $0.69^{a}$ & $0.81^{a}$ & -0.04 & $2.46^{a}$ & $1.30^{a}$ \\
Commercial & 0.22 & $0.72^{a}$ & $1.31^{a}$ & $1.29^{a}$ & $0.78^{a}$ \\
Time & $-0.14^{a}$ & $-0.07^{b}$ & 0.05 & 0.05 & $-0.07^{b}$ \\
Distance & $0.41^{a}$ & 0.15 & -0.15 & 0.12 & $0.38^{a}$ \\
No. stops & $-0.08^{c}$ & -0.07 & -0.03 & -0.06 & $-0.10^{b}$ \\
Information & $0.81^{b}$ & 0.33 & 0.42 & 0.28 & -0.00 \\
Likelihood ratio chi ${ }^{2}$ & 110 & 68 & 38 & 180 & 104 \\
Value of information (min.) & 6 & - & - & - & - \\
\hline Route Rank $=f$ (perceived route attributes, dummy variable, information) & & \\
\hline Esthetics & $0.80^{a}$ & $0.77^{a}$ & 0.14 & $2.60^{a}$ & $1.56^{a}$ \\
Commercial & 0.02 & $0.48^{b}$ & $1.52^{a}$ & $1.53^{a}$ & $0.93^{a}$ \\
Time & $-0.17^{a}$ & $-0.07^{a}$ & 0.00 & -0.00 & $-0.11^{a}$ \\
Distance & -0.05 & 0.05 & 0.00 & $0.12^{b}$ & 0.02 \\
No. stops & $-0.17^{a}$ & $-0.12^{a}$ & -0.04 & -0.06 & $-0.10^{b}$ \\
Information & $0.85^{b}$ & $0.63^{c}$ & 0.37 & 0.36 & 0.12 \\
Likelihood ratio chi ${ }^{2}$ & 190 & 84 & 47 & 194 & 138 \\
Value of information (min.) & 5 & 9 & - & - & - \\
\hline Route Rank $=f$ (cognitive knowledge, dummy variable, information) & & & \\
\hline Esthetics & 0.07 & 0.34 & -0.24 & $1.6^{a}$ & $1.00^{a}$ \\
Commercial & -0.42 & 0.19 & $1.26^{a}$ & $0.77^{a}$ & $0.61^{b}$ \\
Efficiency & $0.58^{a}$ & $0.27^{a}$ & 0.02 & $-0.16^{c}$ & $0.37^{a}$ \\
Easiness & $0.36^{a}$ & $0.19^{c}$ & 0.14 & 0.15 & 0.11 \\
Pleasure & $0.30^{a}$ & $0.22^{a}$ & $0.14^{b}$ & $0.49^{a}$ & $0.23^{a}$ \\
Unfamiliarity & $-0.42^{a}$ & $-0.22^{a}$ & 0.04 & -0.02 & $-0.14^{b}$ \\
Information & 0.37 & 0.19 & 0.17 & -0.03 & -0.21 \\
Likelihood ratio chi ${ }^{a}$ & 247 & 124 & 59 & 238 & 156 \\
\hline & & & & & \\
\hline
\end{tabular}

${ }^{a}$ Statistically significant at level .01 .

${ }^{b}$ Statistically significant at level .05

${ }^{c}$ Statistically significant at level .1. 
TABLE 3 Results: Multinomial Logit Models

\begin{tabular}{lccccc}
\hline Purpose & Commute Trip & Event & Shopping & Recreation & Visit \\
\hline Route Choice $=f$ (observed route attributes, dummy & variable, accurate information) & \\
\hline Esthetics & $1.08^{a}$ & $1.68^{a}$ & -0.56 & $3.60^{a}$ & $2.13^{a}$ \\
Commercial & -1.45 & 0.78 & $1.65^{a}$ & 0.53 & 0.13 \\
Time & $-0.32^{a}$ & $-0.27^{a}$ & 0.07 & -0.01 & $-0.25^{a}$ \\
Distance & $0.80^{a}$ & $0.61^{a}$ & -0.13 & $0.43^{b}$ & $0.88^{a}$ \\
No. stops & -0.01 & 0.01 & -0.04 & $-0.11^{c}$ & -0.07 \\
Unfamiliarity & $-0.26^{a}$ & $-0.13^{b}$ & -0.08 & -0.02 & $-0.14^{b}$ \\
Information & $0.26^{c}$ & $0.24^{c}$ & 0.13 & 0.19 & 0.11 \\
Constant & 0.01 & -0.55 & -0.76 & $-4.4^{a}$ & $-2.29^{a}$ \\
Pseudo- $R^{2}$ & .31 & .19 & .08 & .37 & .24 \\
Value of information (min) & 1 & 1 & - & - & - \\
\hline Route Choice $=f$ (perceived route attributes, dummy & variable, accurate information) & \\
\hline Esthetics & $1.63^{a}$ & $1.9^{a}$ & -0.45 & $3.9^{a}$ & $2.6^{a}$ \\
Commercial & -1.37 & $1.0^{b}$ & $1.76^{a}$ & $1.0^{b}$ & 0.51 \\
Time & $-0.10^{a}$ & $-0.04^{c}$ & -0.02 & -0.04 & $-0.10^{a}$ \\
Distance & $-0.06^{c}$ & -0.01 & $-0.04^{b}$ & 0.01 & -0.05 \\
Speed & $0.08^{a}$ & $0.07^{a}$ & $-0.02^{c}$ & 0.02 & $0.05^{a}$ \\
No. stops & $-0.13^{c}$ & $-0.18^{a}$ & -0.05 & -0.04 & $-0.13^{c}$ \\
Information & $0.42^{a}$ & $0.43^{a}$ & 0.10 & 0.21 & 0.25 \\
Constant & $-2.07^{b}$ & $-3.0^{a}$ & 0.42 & $-2.6^{b}$ & -1.5 \\
Pseudo- $R^{2}$ & .34 & .21 & .10 & .36 & .24 \\
Value of information (min) & 4 & 11 & -10 & - & - \\
\hline Route Choice $=f$ (cognitive knowledge, dummy & variable, information) & 0.56 & $-0.72^{c}$ & $2.8^{a}$ & $1.48^{a}$ \\
\hline Esthetics & $-0.7^{b}$ & -0.27 & $1.55^{a}$ & 0.21 & -0.35 \\
Commercial & $0.88^{a}$ & $0.46^{a}$ & 0.09 & 0.02 & $0.50^{a}$ \\
Efficiency & 0.06 & 0.11 & 0.00 & 0.20 & $0.34^{b}$ \\
Easiness & 0.16 & 0.15 & 0.15 & $0.31^{b}$ & -0.01 \\
Pleasure & $-0.28^{a}$ & $-0.19^{a}$ & -0.02 & -0.03 & $-0.17^{b}$ \\
Unfamiliarity & 0.13 & 0.13 & 0.08 & -0.01 & -0.01 \\
Information & .15 & .09 & .36 & .20 \\
Pseudo- $R^{2}$ & & & & & \\
\hline & & & & & \\
\hline
\end{tabular}

${ }^{a}$ Statistically significant at level .01 .

${ }^{b}$ Statistically significant at level .05 .

${ }^{c}$ Statistically significant at level.1.

TABLE 4 Results: Ordinary Linear Regression Standardized Route Score $=f$ (Cognitive Knowledge, Dummy Variable, Information)

\begin{tabular}{lcccccc}
\hline Purpose & Work & Home & Shopping & Recreation & Event & Visit \\
\hline Esthetics & $0.31^{a}$ & $0.37^{b}$ & $-0.27^{b}$ & $0.61^{a}$ & -0.38 & 0.06 \\
Commercial & 0.05 & 0.04 & $0.49^{a}$ & $0.46^{a}$ & $0.71^{b}$ & 0.33 \\
Efficient & $0.10^{a}$ & $0.08^{a}$ & 0.03 & 0.00 & $0.18^{b}$ & $0.18^{a}$ \\
Easiness & $0.10^{a}$ & $0.10^{a}$ & 0.04 & 0.01 & 0.01 & 0.06 \\
Pleasure & $0.18^{a}$ & $0.18^{a}$ & $0.15^{a}$ & $0.23^{a}$ & $0.31^{a}$ & $0.41^{a}$ \\
Unfamiliarity & $-0.08^{a}$ & $-0.06^{a}$ & -0.01 & -0.02 & $-0.13^{a}$ & $-0.15^{a}$ \\
Information & $0.10^{c}$ & 0.10 & 0.02 & 0.04 & 0.07 & 0.24 \\
Constant & $-1.64^{a}$ & $-1.71^{a}$ & $-1.06^{a}$ & $-1.32^{a}$ & $2.33^{a}$ & $1.81^{a}$ \\
$R^{2}$ & .43 & .41 & .16 & .46 & .13 & .24 \\
\hline
\end{tabular}

${ }^{a}$ Statistically significant at level .01 .

${ }^{b}$ Statistically significant at level .05

${ }^{c}$ Statistically significant at level .1. 
TABLE 5 Routes Selected by Subjects for Different Trip Purposes

\begin{tabular}{llccccccc}
\hline Route & $\begin{array}{l}\text { Time } \\
(\mathrm{min})\end{array}$ & $\begin{array}{l}\text { Distance } \\
(\mathrm{mi})\end{array}$ & Commute & Event & Shopping & Recreation & Visit & Sunday \\
\hline I-94 & $13.35^{a}$ & 7.17 & 76 & 62 & 21 & 16 & 57 & 2 \\
Summit & 19.62 & 7.61 & 29 & 38 & 17 & 81 & 48 & 97 \\
Union & 20.48 & $7.13^{a}$ & 3 & 0 & 30 & 0 & 1 & 0 \\
Grand & 23.81 & 8.04 & 1 & 9 & 35 & 8 & 5 & 7 \\
MS & 24.55 & 7.89 & 4 & 4 & 10 & 8 & 2 & 7 \\
\hline
\end{tabular}

${ }^{a}$ Indicates the fastest or shortest route based on GPS measurements.

(75). Findings in this and previous research clearly show that route choice is a complex spatial behavior sensitive to a number of attributes of the environment and the decision maker. It is therefore a challenging task to develop a universal route choice theory that encompasses the aforementioned empirical evidence and still produces operational models. Traditional route assignment models considering only travel time, however, may have oversimplified the problem. The findings from the choice model in this research may help develop generalized cost that considers both travel time and other important route choice factors. Table 5 summarizes the distribution of routes selected by the subjects for various trip purposes, as well as the actual average travel times and distances of these routes. These user preferences again show that time and distance are not the only factors in route choice behavior.

The presence of pretrip information for a route makes a route more attractive, as demonstrated by positive signs of the variable information in all models. A brief discussion of this variable is worthwhile. Information is a dummy variable; that is, 1 if a subject rated the accuracy of the information greater than 5 on a 7-point scale, and 0 otherwise. Another variable, information presence, has also been examined, which is 1 as long as traveler information is provided before a trip and 0 otherwise. However, information presence is not statistically significant in all models, fails to pass specification $F$ test, and therefore was dropped from the final models. Information (or more precisely "accurate information") is statistically significant for commute and event trips in Tables 2 and 3, which is intuitive. It is not significant for trips with other purposes. These results also confirm findings from some previous studies that the quality and accuracy of traveler information is crucial to the success of ATIS.

In the after-experiment survey, subjects also directly rated their perceived importance of traveler information for trips with various purposes. The findings are summarized in Table 6 , and consistent with the results from statistical models. It should be noted that eight subjects believed information to be the least important for commute trips. Four of these subjects walked, biked, or carpooled (as passengers) to work.

Finally, by comparing overall model explanatory power among Table 2 (likelihood ratio), cognitive route knowledge (Table 2) in all cases explains route choice behavior significantly better than perceived route attributes (Table 2 ), which explain route choice significantly better than observed route attributes (Table 2). This suggests that there may be a structure in the route perception and cognition process, as illustrated in Figure 2. Most choice models applied to study human spatial behavior tend to relate observed attributes directly to the final choice, ignoring the perception and cognition process. These findings suggest that it should be worthwhile to model route perception and cognition processes explicitly, which calls for corresponding development in spatial choice theory, a promising future research direction.

\section{Value of Information by Trip Purposes, Routes, and Level of Congestion}

The elasticity between the presence of accurate information and travel time in the route choice models is a measure of the value of information in terms of equivalent time savings. The value of information clearly depends on a number of factors. Results suggest that the provision of information is especially valuable for commute and event trips. On the basis of the rank-ordered logit models (Table 2), the value of pretrip information for commute trips is approximately equivalent to a 5-min time savings. Information is more valuable for event trips ( $9 \mathrm{~min}$ ) on a per-trip basis. It is possible that pretrip traveltime information can more significantly reduce schedule delay or

TABLE 6 Importance of Information and Trip Purpose

\begin{tabular}{lcccccc}
\hline Rank & Commute & Event & Shopping & Recreation & Visit & Sunday \\
\hline First & 31 & 10 & 2 & 2 & 3 & 5 \\
Second & 4 & 25 & 10 & 6 & 5 & 1 \\
Third & 1 & 6 & 18 & 13 & 12 & 3 \\
Fourth & 3 & 8 & 5 & 19 & 11 & 4 \\
Fifth & 3 & 1 & 14 & 9 & 16 & 5 \\
Last & 8 & 1 & 1 & 0 & 3 & 32 \\
Average & 2.3 & 2.4 & 3.4 & 3.6 & 3.8 & 5.0 \\
Effective sample size: 50 & & & & & \\
\hline
\end{tabular}


travel-time delay cost for event trips than for other trips because event trips are typically characterized by time pressure and uncertainty (e.g., unfamiliarity with the routes to event destinations, parking waiting time). On a separate note, value of time itself may vary with trip purposes. For instance, saving $5 \mathrm{~min}$ for commute trips is different from saving $5 \mathrm{~min}$ for recreational trips. Because the variation of value of time has not been adequately studied in previous research, value of time is assumed to be $\$ 10 / \mathrm{h}$ for all trips. Multinomial logit models (Table 3 ) provide similar value-of-information results with higher variation (1 actual min and 4 perceived min for commute trips, 1 actual min and 11 perceived min for event trips). If the time savings are converted into dollars, the monetary value of information ranges form $\$ 0.15$ to $\$ 1$ per trip. Travelers do not appear to be willing to pay for travel-time information for shopping and recreational trips.

It has also been hypothesized that the perceived value of information would be higher when the level of congestion on a route is higher. At least, the actual benefit of traveler information is higher in a moderately congested commute corridor than in an uncongested corridor (3). Kanafani and Al-Deek argued that the benefits of ATIS are negatively related to the speed of arterial streets (12). By using the standardized route score as the dependent variable, the value of information for the five selected routes could be differentiated. (This is not possible in logit models with choice or rank as the dependent variable.) Results from these regression models allowed the value of information to be plotted against various route attributes. The ratio of the average travel speed of all subjects to the design speed, defined as the 95th percentile speed, is used in Figure 3 as an indicator of congestion. There is some evidence that information is more valuable on routes with higher congestion, but there are exceptions (event trips in Figure $3 a$ ). Imagine that a traveler is planning a trip. What is valuable to him or her is the travel-time information on both the planned route and alternative route. By the design of the field experiment, results in Figure $3 a$ reflect only the value of traveltime information for the planned route. Future studies should design more sophisticated experiments with real driving tasks (e.g., actual home-to-work trips) and various information provision strategies. In terms of the monetary value of information, the regression models generate results similar to logit choice models. There is variation for different trip purposes, but travelers would pay no more than $\$ 1$ for pretrip travel-time information.

When completing the after-experiment survey, subjects were asked directly how much they would be willing to pay for the pretrip travel-time information they had received. Sixty-five percent of subjects said that they would not pay for such service; $29 \%$ were willing to pay $\$ 1$ to $\$ 5$, and $6 \%$ were willing to pay $\$ 6$ to $\$ 10$. The average willingness-to-pay is approximately $\$ 1.40$ per trip, with a large standard deviation of $\$ 2.70$.

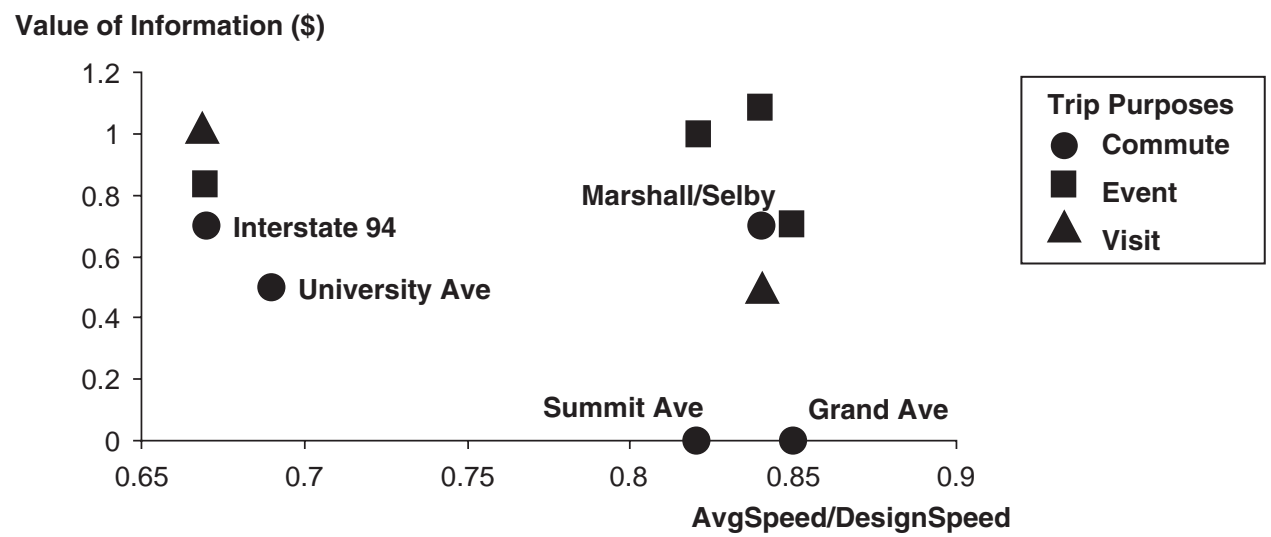

(a)

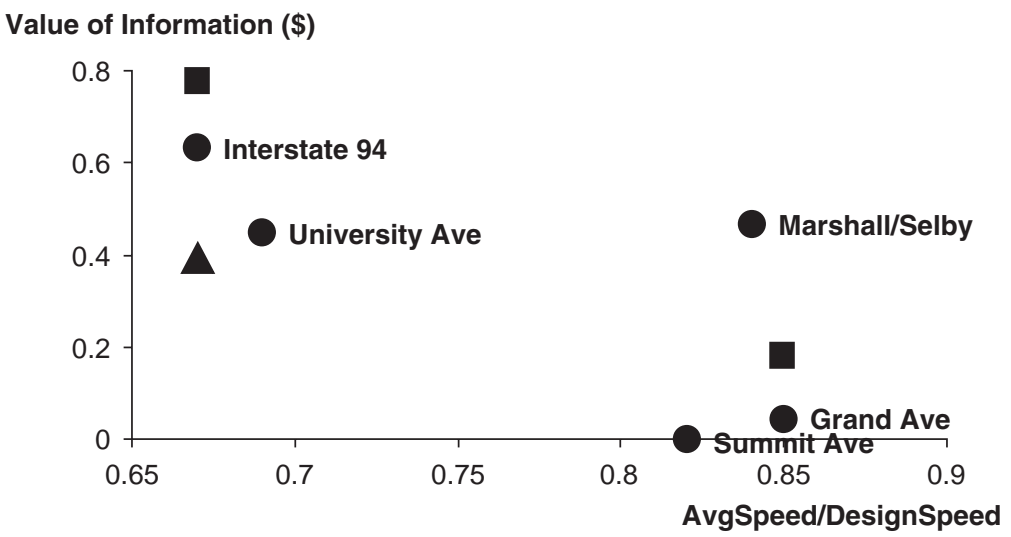

(b)

FIGURE 3 Value of traveler information by route, trip purpose, and level of congestion: $(a)$ model: standardized route score $=f$ (observed road attributes, information) and $(b)$ model: standardized route score $=f$ (perceived road attributes, information). 
Wolinetz et al. investigated travelers' willingness to pay for information in the 1998 San Francisco (California) Bay Area survey (21). In their study, survey participants were asked to report their willingness to pay for travel-time information on usual and alternative routes and alternative route planner. They found that, on average, travelers were willing to pay $\$ 0.74$ on a per-call basis and $\$ 3.84$ per month for such information. By surveying TravInfo callers, Khattak et al. found that travelers' willingness to pay is positively related to customization of information, trip characteristics, and personal attributes (22). Although the results of the current study suggest that trip purpose is a very important factor, personal attributes, such as age, gender, and income, were not significant in the regression model.

Several previous studies discussed the importance of providing customized information to travelers according to their O-D pairs, travel patterns, familiarity with the corridor, and individual characteristics $(12,31)$. It should be noted that the pretrip travel-time information provided in the field experiment is customized to the O-D pair, because there is only one O-D pair in the experiment. The value of this type of information should be higher than more general traveler information, such as expected delay time on a specific route segment displayed on a variable message sign. Adler and Blue presented an interesting method for providing travelers with more personalized planning assistance using artificial intelligence techniques (76).

\section{Determinants of Information Usage and Public Acceptance of ATIS}

Table 7 summarizes estimation results of information usage models developed earlier. The following factors positively affect the usage of traveler information: information accuracy, positive attitude toward information services, commute time, household vehicle ownership, and ownership of PCs and personal digital assistants. The elderly population ( $>55$ years) tends to use traveler information less often than others.

The market for for-profit private traveler information service is not negligible according to the results of this study. Approximately $35 \%$ of subjects in the experiment expressed their willingness to pay

TABLE 7 Information Usage

\begin{tabular}{|c|c|c|}
\hline \multirow[b]{2}{*}{ Independent Variable } & \multicolumn{2}{|l|}{ Dependent Variable } \\
\hline & $\begin{array}{l}\text { Frequency of Using } \\
\text { Info. Scale } 1-6 \\
\text { (most often) } \\
\text { Ordinary Regression }\end{array}$ & $\begin{array}{l}\text { Information } \\
\text { Usage (1: often: } \\
\text { 0: not often) } \\
\text { Binary Logit }\end{array}$ \\
\hline $\begin{array}{l}\text { Accuracy of information } \\
\quad(1-7 \text { scale })\end{array}$ & 0.27 & $3.42^{a}$ \\
\hline Positive attitude (1-7 scale) & $0.58^{b}$ & $3.32^{b}$ \\
\hline Commute time (min) & $0.03^{c}$ & $0.38^{a}$ \\
\hline No. of household vehicles & -0.16 & $8.00^{a}$ \\
\hline Age ( 0 if $>55,1$ otherwise $)$ & $-1.35^{a}$ & $-12.70^{b}$ \\
\hline No. of PCs and PDAs & $0.81^{a}$ & 2.72 \\
\hline Constant & $-2.92^{a}$ & $-61^{b}$ \\
\hline$R^{2}$ or pseudo- $R^{2}$ & .39 & .77 \\
\hline Sample size & $43^{d}$ & 43 \\
\hline
\end{tabular}

${ }^{a}$ Statistically significant at .1.

${ }^{b}$ Statistically significant at .05 .

${ }^{c}$ Statistically significant at .01 .

${ }^{d}$ Only subjects provided with pretrip information are included. for such service. ATIS should be provided by the private sector at a charge to users, probably with the belief that the private sector would be able to provide more reliable and better service, according to $19 \%$ of subjects. However, the majority of the sample (70\%) considered the public sector to be the most appropriate provider of free traveler information. Wolinetz et al. (21) found that $48.5 \%$ survey participants were willing to pay for traveler information. It is not surprising that a larger percentage was found in their study because respondents were notified that they would receive information for both their usual routes and alternative routes.

The importance of the accuracy of information has already been discussed. When the traveler information is perceived to be inaccurate, there may not be any demand for such information services at all. Bad information, even occasional, could hurt the credibility of the service and create uncertainty in the quality of information itself.

\section{CONCLUSIONS}

The success of ATIS depends on travelers' responses to the information, which are contingent on a number of properties of the information itself: quality, accuracy, usefulness, timeliness, user customization, cost, and the manner in which information is provided. Findings in the study suggest that travelers are willing to pay for traveler information, although the perceived value of information varies by trip purposes and route attributes. In most cases, drivers are willing to pay no more than $\$ 1 /$ trip for pretrip travel-time information. This conclusion is drawn from the field experience stated preference surveys, regression models, and discrete choice models developed in this research.

However, the task of understanding drivers' responses to information is challenging. Most studies using traditional route equilibrium assignment models tend to make assumptions about the role of information in reducing or eliminating perception errors. Given the various types of traveler information, various means of providing information, and the various tastes of drivers, theoretical studies based on static and even dynamic assignment models may have limited value in guiding the design and evaluation of ATIS. Survey techniques have been used to explore likely user responses and willingness to pay for ATIS. Field experiments, in which the behavior of travelers driving in real networks and performing real travel tasks with and without information services is monitored, appear to be a promising future research direction. The experiment of this study provides several lessons for the design of similar and more comprehensive ATIS-related experiments. First, technologies such as GPS vehicle positioning systems are valuable and provide accurate measures of routes traveled by the subjects. Second, combining GPS data with pre- and post-experiment surveys appears to be a promising experimental design methodology. In the survey, subjects can report their perceived route attributes, perceived accuracy of information, and other important information. However, the survey must be carefully designed because subjects may confuse the experiment context with their daily routines. For instance, in this experiment, some subjects rated the importance of information for commute trips on the basis of their routine daily commute trips, whereas some others might have given scores based on the four trips they drove during the experiment. Pretests for both the field experiment and survey questionnaire are necessary. Techniques for combing data from stated and revealed preference surveys have been developed and applied for value-of-time studies (77). They could also be used to design future experiments valuing ATIS. 
Another research need is the development of behavioral theories explaining how information provided by ATIS affects travelers' spatial perception, cognition, and decision-making process in a complex, dynamic, and uncertain transportation network. The theory should be able to generate testable hypotheses for empirical studies using survey techniques or field experiments.

The net social benefits of ATIS come from several sources: user benefits, which are the differences between willingness to pay and the cost of providing the information; benefits for users not using traveler information; and other social benefits resulting from reduced levels of congestion (pollution emissions and fuel consumption). A rigorous economic appraisal of ATIS should be sought for operational traveler information systems. Understanding willingness to pay is only the first step.

Finally, it is also evident from the analysis that a number of factors affect route choice behavior, and travel time is just one of them. However, in discrete route choice and equilibrium route assignment models, the main independent variable that differentiates a driver's choice of route is typically travel time. This is primarily because other information about the quality of the trip or the valuation of the components of travel time (e.g., delay, stopped time, aesthetics) has been unavailable. The research trend in travel demand forecasting of moving toward disaggregate- and even individual-level models calls for better understanding of route choice at the microscopic level. Future studies should seek to incorporate more route attributes in route choice models and develop spatial behavioral theories that can be applied to study route choice.

\section{REFERENCES}

1. Hensher, D. A., and P. B. Goodwin. The Transport Determinants of Travel Choices: An Overview. In The Determinants of Travel Choices (D. A. Hensher and M. Q. Dalvi, eds.), Teakfield Saxon House Studies, Farnborough, United Kingdom, 1978.

2. Golledge, R. G., and R. J. Stimson. Spatial Behavior: A Geographic Perspective. Guilford Press, New York, 1997.

3. Levinson, D. M. The Value of Advanced Traveler Information Systems for Route Choice. Transportation Research C, Vol. 11, 2003, pp. 75-87.

4. Hensher, D. A. The Value of Commuter Travel Time Savings: Empirical Estimation Using an Alternative Valuation Model. Journal of Transport Economics and Policy, Vol. 10, No. 2, 1975, pp. 167-176.

5. Bates, J. Measuring Travel Time Values with a Discrete Choice Model: A Note. Economic Journal, Vol. 97, 1987, pp. 493-498.

6. Jara-Díaz, S. Consumer's Surplus and the Value of Travel Time Savings. Transportation Research B, Vol. 24, 1990, pp. 73-77.

7. Hensher, D. A. Measurement of the Valuation of Travel Time Savings. Journal of Transport Economics and Policy, Vol. 35, No. 1, 2001, pp. 71-98.

8. Jara-Díaz, S. Allocation and Valuation of Travel Time Savings. In Handbook of Transport Modeling Volume 1 (D. A. Hensher and K. J. Button, eds.), Elsevier Science, Oxford, United Kingdom, 2000, pp. 303-319.

9. Hensher, D. A., and P. B. Goodwin. Implementation of Values of Time Savings: The Extended Set of Considerations in a Tollroad Context. Transport Policy, Vol. 11, No. 2, 2004, pp. 171-181.

10. Small, K. A., R. B. Noland, and P. Koskenoja. Socio-Economic Attributes and Impacts of Travel Reliability: A Stated Preference Approach. PATH Report, MOU-117, California Partners for Advanced Transit and Highways, University of California, Berkeley, 1995.

11. Small, K. A., R. B. Noland, X. Chu, and D. Lewis. NCHRP Report 431: Variation of Travel-Time Savings and Predictability in Congested Conditions for Highway User-Cost Estimation. TRB, National Research Council, Washington, D.C., 1999.

12. Kanafani, A., and H. M. Al-Deek. A Simple Model for Route Guidance Benefits. Transportation Research B, Vol. 25, 1991, pp. 191-201.

13. Emmerink, R. H. M., K. W. Axhausen, and P. Rietveld. Effects of Information in Road Transport Networks with Recurrent Congestion. Transportation, Vol. 22, 1995, pp. 21-53.
14. Wunderlich, K. E. Congestion and Route Guidance Benefits Assessment Letter ITS-L-131. The MITRE Corporation, McLean,Va., 1995.

15. Emmerink, R. H. M., E. T. Verhoef, P. Nijkamp, and P. Rietveld. Information Provision in Road Transport with Elastic Demand. Journal of Transport Economics and Policy, Vol. 30, No. 2, 1996, pp. 117-136.

16. Inman, V. W., and J. I. Peters. TravTek Global Evaluation Study. FHWARD-96-031. FHWA, U.S. Department of Transportation, Washington, D.C., 1996.

17. Peckmann, M. STORM Stuttgart Transport Operation by Regional Management Results on the Field: Trials and Assessment. Presented at Third Annual World Congress on Intelligent Transport Systems: Intelligent Transportation: Realizing the Future, Orlando, Fla., 1996.

18. Wunderlich, K. E. An Assessment of Pre-Trip and En Route ATIS Benefits in a Simulated Regional Urban Network. Presented at Third World Congress on Intelligent Transport Systems, Intelligent Transportation: Realizing the Future, Orlando, Fla., 1996.

19. Adler, J. L., V. J. Blue, and T.-L. Wu. Assessing Network and Driver Benefits from Bi-Objective In-Vehicle Route Guidance. Presented at 78th Annual Meeting of the Transportation Research Board, Washington, D.C., 1999.

20. Hall, R. W. Non-Recurrent Congestion: How Big Is the Problem? Are Travelers Information Systems the Solution? Transportation Research C, Vol. 1, 1993, pp. 89-103.

21. Wolinetz, L. D., A. J. Khattak, and Y. Yim. Why Will Some Individuals Pay for Travel Information When It Can Be Free? Analysis of a Bay Area Traveler Survey. In Transportation Research Record: Journal of the Transportation Research Board, No. 1759, TRB, National Research Council, Washington, D.C., 2001, pp. 9-18.

22. Khattak, A. J., Y. Yim, and L. Stalker. Willingness to Pay for Travel Information. Transportation Research C, Vol. 11, 2003, pp. 137-159.

23. Muizelaar, T. J., and B. van Arem. Drivers' Preferences for Traffic Information for Nonrecurrent Traffic Situations. In Transportation Research Record: Journal of the Transportation Research Board, No. 2018, Transportation Research Board of the National Academies, Washington, D.C., 2007, pp.72-79.

24. Hall, R. W. Route Choice and Advanced Traveler Information Systems on a Capacitated and Dynamic Network. Transportation Research C, Vol. 4, 1996, pp. 289-306.

25. Al-Deek, H. M., S. S. Ishak, and A. E. Radwan. Impact of Traffic Diversion with ATIS on Travelers' Safety. Computers and Industrial Engineering. Vol. 34, No. 2, 1998, pp. 547-558.

26. Khattak, A. J., F. Targa, and Y. Yim. Advanced Traveler Information Systems: Relationship to Traveler Behavior. In Assessing the Benefits and Costs of ITS (D. Gillen and D. Levinson, eds.), Kluwer Academic Publishers, Norwell, Mass., 2004, pp. 217-240.

27. Van Vuren, T., D. Van Vliet, and M. J. Smith. Combined Equilibrium in a Network with Partial Route Guidance. In Traffic Control Methods (S. Yagar and S. E. Rowe, eds.), Engineering Foundation, New York, 1989, pp. 375-387.

28. Koutsopoulos, H. N., and T. Lotan. Motorist Information Systems and Recurrent Traffic Congestion: Sensitivity Analysis of Expected Results. In Transportation Research Record 1281, TRB, National Research Council, Washington, D.C., 1990, pp. 145-158.

29. Ben-Akiva, M., A. de Palma, and I. Kaysi. Dynamic Network Models and Driver Information Systems. Transportation Research A, Vol. 25 1991, pp. 251-266.

30. Mahmassani, H. S., and R. Jayakrishnan. System Performance and User Response Under Real-Time Information in a Congested Traffic Corridor. Transportation Research A, Vol. 25, 1991, pp. 293-307.

31. Al-Deek, H. M., and A. Kanafani. Modeling the Benefits of Advanced Traveler Information Systems in Corridors with Incidents. Transportation Research C, Vol. 1, 1993, pp. 303-324.

32. Khattak, A. J., J. L. Schofer, and F. S. Koppelman. Commuters' Enroute Diversion and Return Decisions: Analysis and Implications for Advanced Travelers Information Systems. Transportation Research A, Vol. 27, 1993, pp. 101-111.

33. Koutsopoulos, H. N., and H. Xu. An Information Discounting Routing Strategy for Advanced Traveler Information Systems. Transportation Research C, Vol. 1, 1993, pp. 249-264.

34. Polydoropoulou, A., M. Ben-Akiva, and I. Kaysi. Revealed Preference Models of the Influence of Traffic Information on Driver's Route Choice Behavior. In Transportation Research Record 1453, TRB, National Research Council, Washington, D.C., 1994, pp. 56-65.

35. Chang, G. L., and T. Junchaya. A Dynamic Route Assignment Model for Guided and Unguided Vehicles with a Massively Parallel Computing 
Architecture. Mathematical and Computer Modelling, Vol. 22, 1995 , pp. 377-395.

36. Abdel-Aty, M. A., R. Kitamura, and P. P. Jovanis. Using Stated Preference Data for Studying the Effect of Advanced Traffic Information on Drivers' Route Choice. Transportation Research C, Vol. 5, 1997, pp. 39-50.

37. Maher, M. J., and P. C. Hughes. Estimation of the Potential Benefits from an ATT System Using a Multiple User Class Stochastic User Equilibrium Assignment Model. In Applications of Advanced Technologies in Transportation Engineering (Y. J. Stephanedes and F. Filippi, eds.). Proc., 4th International Conference, Capri, Italy, American Society of Civil Engineers, New York, 1996, pp. 700-704.

38. Deakin, A. K. Factoring Motorists' Responses to the 1994 Northridge Earthquake. Computer, Environment, and Urban Systems, Vol. 21, 1997, pp. 335-357.

39. Jha, M., S. Madanat, and S. Peeta. Perception Updating and Day-ToDay Travel Choice Dynamics in Traffic Networks with Information Provision. Transportation Research C, Vol. 6, 1998, pp. 189-212.

40. Yang, H. Multiple Equilibrium Behaviors and Advanced Traveler Information Systems with Endogenous Market Penetration. Transportation Research B, Vol. 32, 1998, pp. 205-218.

41. Wunderlich, K. E. A Simulation-Based Assessment of Route Guidance Benefits under Variable Network Congestion Conditions. Mathematical and Computer Modelling, Vol. 27, 1998, pp. 87-101.

42. Yang, H., and Q. Meng. Modeling User Adoption of Advanced Traveler Information Systems: Dynamic Evolution and Stationary Equilibrium. Transportation Research A, Vol. 35, 2001, pp. 895-912.

43. Lo, H., and W. Y. Szeto. A Methodology for Sustainable Traveler Information Services. Transportation Research B, Vol. 36, 2002, pp. 113-130.

44. Wahle, J., A. L. C. Bazzan, F. Klügl, and M. Schreckenberg. The Impact of Real-Time Information in a Two-Route Scenario Using Agent-Based Simulation. Transportation Research C, Vol. 10, 2002, pp. 399-417.

45. Pattanamekar, P., D. Park, L. R. Rilett, J. Lee, and C. Lee. Dynamic and Stochastic Shortest Path in Transportation Networks with Two Components of Travel Time Uncertainty. Transportation Research C, Vol. 11, 2003, pp. 331-354.

46. Srinivasan, K. K., and H. S. Mahmassani. Analyzing Heterogeneity and Unobserved Structural Effects in Route-Switching Behavior under ATIS: A Dynamic Kernel Logit Formulation. Transportation Research B, Vol. 37, 2003, pp. 793-814.

47. Yin, Y., and H. Yang. Simultaneous Determination of the Equilibrium Market Penetration and Compliance Rate of Advanced Traveler Information Systems. Transportation Research A, Vol. 37, 2003, pp. 165-181.

48. Lo, H. K., and W. Y. Szeto. Modeling Advanced Traveler Information Services: Static Versus Dynamic Paradigms. Transportation Research B, Vol. 38, 2004, pp. 495-515.

49. Mahmassani, H. S., N. N. Huynha, K. K. Srinivasan, and M. Kraanc. Tripmaker Choice Behavior for Shopping Trips under Real-Time Information: Model Formulation and Results of Stated-Preference InternetBased Interactive Experiments. Journal of Retailing and Consumer Services, Vol. 10, 2003, pp. 311-321.

50. Bhat, C. R., J. L. Schofer, F. S. Koppelman, and R. C. Bautch. Driver Recruitability for Advanced Traveler Information System Experiments. Transportation Research C, Vol. 4, 1993, pp. 265-274.

51. Mahmassani, H. S., and P. S.-T. Chen. Comparative Assessment of Origin-Based and En Route Real-Time Information Under Alternative User Behavior Rules. In Transportation Research Record 1306, TRB, National Research Council, Washington, D.C., 1991, pp. 69-81.

52. Schiller, J., and A. Voisard (eds.). Location-Based Services. Elsevier Science, San Francisco, Calif., 2004.

53. Ng, L., W. Barfield, and F. Mannering. A Survey-Based Methodology to Determine Information Requirements for Advanced Traveler Information Systems. Transportation Research C, Vol. 3, 1995, pp. 113-127.

54. Gilroy, R., R. Puentes, and R. Schuman, (eds.). Choosing the Route to Traveler Information Systems Deployment: Decision Factors for Creating Public-Private Business Plans. ITS America, Washington D.C., 1998.
55. Levinson, D. M. The Economics of Traveler Information from Probes. Public Works Management and Policy, Vol. 6, No. 4, 2002, pp. 241-249.

56. Behnke, R. California Smart Traveler System. USDOT Report No. DOT-T-92-16. U.S. Department of Transportation, 1992.

57. Perez, W. A., R. N. Fleischman, G. Golembiewski, and D. Dennard. TravTek Field Study Results to Date. Proc., IVHS America 1993 Annual Meeting, IVHS America, Washington, D.C., 1993, pp. 667-673.

58. Ligas, J., S. Bowcott, D. Boyce, P. Nelson, J. L. Schofer, F. S. Koppelman, and A. Kirson. An Update on ADVANCE. Proc., IVHS America 1993 Annual Meeting, IVHS America, Washington, D.C., 1993, pp. 621-625.

59. Barbaresso, J., and J. Grubba. Overview of the FASTTRAC IVHS Program. Proc., IVHS America 1993 Annual Meeting, IVHS America, Washington, D.C., 1993, pp. 630-637.

60. Slovic, P., B. Fischoff, and L. Lichtenstein. Behavioral Decision Theory. Annual Review of Psychology, Vol. 28, 1977, pp. 1-40.

61. Svenson, O. Process Descriptions of Decision-Making. Organizational Behavior and Human Performance, Vol. 23, 1979, pp. 86-112.

62. Ben-Akiva, M., and S. R. Lerman. Discrete Choice Analysis: Theory and Application to Travel Demand. MIT Press, Cambridge, Mass., 1985.

63. Arentze, T., and H. J. P. Timmermans. ALBATROSS: A Learning-Based Transportation Oriented Simulation System. EIRSS, Eindhoven, Netherlands, 2000.

64. Manski, C. The Structure of Random Utility Models. Theory and Decision, Vol. 8, 1977, pp. 229-254.

65. McFadden, D. Conditional Logit Analysis of Qualitative Choice Behavior. In Frontiers in Econometrics (P. Zarembka, ed.). Academic Press, New York, 1974, pp. 105-142.

66. Koop, G., and D. J. Poirier. Rank-Ordered Logit Models: An Empirical Analysis of Ontario Voter Preferences. Journal of Applied Econometrics, Vol. 9, No. 4, 1994, pp. 369-388.

67. Golledge, R. G. Geographical Theories. International Social Science Journal, Vol. 150, 1996, pp. 461-476.

68. Benshoof, J. A. Characteristics of Drivers' Route Selection Behavior Traffic Engineering and Control, Vol. 11, No. 12, 1970, pp. 604-609.

69. Vaziri, M., and T. N. Lam. Perceived Factors Affecting Driver Route Decisions. Journal of Transportation Engineering, Vol. 109, No. 2, 1983, pp. 297-311.

70. Ben-Akiva, M., M. J. Bergman, A. J. Daly, and R. Ramaswamy. Modeling Inter-Urban Route Choice Behavior. Proc., 9th International Symposium on Transportation and Traffic Theory. (J. Volmuller and R. Hamerslag, eds.). VNU Science Press, Utrecht, Netherlands, 1984, pp. 299-330.

71. Bovy, P. H. L., and E. Stern. Route Choice: Wayfinding in Transport Networks. Kluwer Academic Publishers, Dordrecht, Netherlands, 1990.

72. Wachs, M. Relationships Between Drivers' Attitudes Toward Alternate Routes and Driver and Route Characteristics. In Highway Research Record 197, HRB, National Research Council, Washington, D.C., 1967 pp. $70-87$.

73. Ulrich, S. R. Scenery and the Shopping Trip: The Roadside Environment as a Factor in Route Choice, Department of Geography, University of Michigan, Ann Arbor, Vol. 12, 1974.

74. Stern, E., and D. Leiser. Levels of Spatial Knowledge and Urban Travel Modeling. Geographical Analysis, Vol. 20, No. 2, 1988, pp. 140-155.

75. Stern, E., and D. Leiser. A Cognitive Utility Model of Urban Route Choice. Report for the Israel National Academy of Science, Beer Sheva, Israel, 1989.

76. Adler, J. L., and V. J. Blue. Toward the Design of Intelligent Traveler Information Systems. Transportation Research C, Vol. 6, 1998, pp. 157-172.

77. Louviere, J. J., and D. A. Hensher. Combining Preference Data. In The Leading Edge of Travel Behaviour Research (D. A. Hensher, ed.), Pergamon Press, Oxford, United Kingdom, 2001.

The Intelligent Transportation Systems Committee sponsored publication of this paper. 